\title{
Residential Operational Energy Use
}

\author{
Peter Rickwood*
}

This is an early draft, circa late 2008

Go to the journal Urban Policy and Research for the real thing

\begin{abstract}
Despite decades of debate in urban research about the effect of built form on household energy use, the empirical research on the topic is still far from conclusive. Many studies rely on small samples and fail to control for crucial variables such as household income. This paper describes a detailed analysis of household energy use in Sydney that controls for major household demographic and income variables. The results demonstrate that appliance ownership, household size, dwelling size and dwelling type all affect energy consumption. Importantly, from a planning perspective, energy use is estimated as 15-20\% lower in units and townhouses/semis, after controlling for other factors.
\end{abstract}

\section{Introduction}

Our understanding of the household-level factors influencing residential in-dwelling energy consumption is limited by the availability of detailed household level end-use data accompanied by demographic and dwelling structure data. While studies of aggregate consumption data have provided estimates of income elasticities of demand for energy, and can even include aggregate-level demographic influences, the lack of recent Australian household-level energy consumption

*peter.rickwood@unsw.edu.au 
analyses places very strong limits on our ability to predict the changes in energy consumption that are likely to result from particular planning policies, such as urban consolidation, or even from social and economic trends, such as the strong one toward higher housing consumption (in terms of $\mathrm{m}^{2}$ of inhabited dwelling per capita). For those interested in how planning can influence energy use, this is clearly a problem. This paper contributes to alleviating the problem by first reviewing existing work in the area, and then analysing three detailed household level datasets of energy use in Sydney. The datasets used are, to the author's knowledge, the largest used in any peer-reviewed research on household level factors influencing residential energy use in Australia.

The remaineder of this article is structured as follows: Section 2 reviews previous studies in this area; Section 3 outlines why a regression approach to modelling has been used in this study; Section 4 details the data sets used; Section 5 contains anaylsis and results; and finally, section 6 discusses the results.

\section{Prior Work}

The sheer number of studies on energy use makes it impractical to detail them all, and so only a selection of what are regarded as most relevant is covered. Research published prior to 1995 is not covered, as the well documented changes in energy use patterns, such as the trend toward air-conditioning and higher appliance-related energy use, is sufficiently strong that older research is of limited use in understanding contemporary energy use patterns. With a few exceptions, attention is focused on research into energy use in Australian households, as inter-country differences in household energy use provide limited insights due to differences in energy resource availability, prices, and social norms. A great body of work by economists and econometricians analysing aggregate energy consumption is also not reviewed, as it is of limited use in understanding household level residential energy use. While acknowledging the importance of embodied and transport-related energy consumption, this paper is concerned 
only with in-home operational energy use. Recent Austrlian reviews of the influence of urban form on both embodied and operational energy use have been provided by Bunker and Holloway (2006); Rickwood et al. (2008).

Agreeing with Perkins (2003)[page 6], delivered (i.e. end-use) energy is chosen as the most appropriate measure for determining the effect of built form on energy use. Changes to fuel mix and electricity generation sources (such as coal $\rightarrow$ wind), or improvements in generation efficiency will alter household primary energy use and greenhouse gas emissions (GGEs), but are of less relevance in a planning context, as they usually occur more-or-less independently of changes to urban structure, dwelling type, and household structure. Where possible, other researchers' estimates of energy use are reported in delivered energy terms, but where this is not possible ${ }^{1}$, other measures of energy use, such as primary energy or GGEs, are reported.

\subsection{Descriptive studies}

Many studies have been concerned with obtaining an accurate picture of how energy is used in residential households, but stop short of any concerted attempt to determine what the underlying factors driving energy use are. For example, NSW Independent Pricing and Regulatory Tribunal (2004, 2006) give detailed break-downs of household energy use by different household types, and by households on different incomes, showing, unsurprisingly, that larger households use more energy, and higher income households use more energy. But higher income is associated with other variables (such as home-ownership) that may also affect energy use. Without an attempt to control for demographic differences, such descriptive work is useful in providing intuition and provoking further research, but cannot be relied upon for predicting the energy use of an individual household, and so is of limited use in informing planners. Similarly, the study by Myors et al. (2005), which reported high per-capita energy use in high-rise buildings (compared to detached), has been useful in challenging

\footnotetext{
${ }^{1}$ If, for example, the conversion factors to primary energy or GGEs are unstated or unclear.
} 
assertions by advocates of urban consolidation that higher density living is necessarily less energy intense (Randolph and Troy, 2007). It does not, however, constitute conclusive evidence that high-rise dwellings cause an increase in energy use, as the study did not control for things such as dwelling age or occupant income and demographics.

The most plentiful source of descriptive information on household energy use is the Australian Bureau of Statistics (ABS). Numerous studies detail the trends to smaller households, larger dwellings, and increased use of air-conditioners (see Australian Bureau of Statistics (2007) for the most recent study). Information on attitudes to energy use and conservation, and appliance ownership, is also provided on an irregular basis through studies such as Australian Bureau of Statistics (2005). While the ABS does not publish household level energy use data, expenditure on energy is available at the household level through Household Expenditure Surveys (HES) (Australian Bureau of Statistics, 2004).

The much cited study by Harrington and Foster (1999), which has been widely relied upon for information on residential energy use in Australia contains valuable descriptive information, much of which is sourced from an end-use study of around 300 NSW households (Pacific Power, 1994). A separate detailed study by Pears (1998) also provides a valuable and detailed description of residential energy trends in Australia. In addition to trends already apparent from ABS data, both studies note the trend to conditioned dwellings, and the increase in the relative contribution of household appliances to total energy use.

Troy et al. (2003) estimated embodied and operational in-dwelling energy use, as well as transport energy use, for selected districts in Adelaide, but the authors themselves pointed out that the lack of demographic and other control variables did not allow them to draw any conclusions that might be useful in informing planning policies.

Although it is not a study of Australian households, the study by Isaacs et al. (2006) of New Zealand households should be mentioned, as it constitutes the most recent, most comprehensive study on household energy use in any country 
that can be regarded as culturally similar to Australia. Although it contains much useful descriptive information on household energy use, this study also contained a number of detailed analyses, which are covered in section 2.2. On a purely descriptive front, New Zealand household energy use reported by Isaacs et al. (2006) follows broadly similar patterns to those in the Australian research: higher income households use more energy; larger households use more energy; use of air-conditioning is increasing; energy use by households appliances, and especially audio-visual ones, are increasing more rapidly than overall household energy use.

\subsection{Regression models based on household surveys/audits}

In this approach, household energy use data is used to estimate a regression model with relevant variables describing the household's socio-economic status, the dwelling occupied by that household, the appliances owned by that household, and the behaviour of the household. The complexity of the regression model that can be estimated is limited by the data available. In the rare case where detailed appliance ownership data is available together with appliance specific energy use information (i.e. appliance logging), a detailed conditional demand analysis (CDA) can be performed. Let $y_{i, j}$ be the amount of energy used in end-use $j$ by household $i ; \zeta_{i}$ be a vector of household variables (income, household type, dwelling type, etc.) about household $i$. The detailed CDA regression model then takes the form:

$$
y_{i, j}=\gamma_{j}+\phi_{j} \zeta_{i}+\epsilon_{i, j}
$$

where $\phi_{j}$ are the parameters to be estimated relating to the household variables $\zeta_{i}$, and $\epsilon_{i, j}$ is the error term. Bartels and Fiebig (2000) use just such a model to analyze the data from a household energy end-use study by energy utilities (Pacific Power, 1994). Results from these two studies jointly provide 
much of the detailed information we currently have about residential end-use energy consumption in Australia.

The expense of direct metering still makes studies such as that by Bartels and Fiebig (2000) rare, and most CDA regressions rely on household level metering only, together with detailed appliance ownership information for each household. In the absence of detailed appliance ownership data, the simplest regression approach is to relate household and dwelling characteristics $\left(\zeta_{i}\right)$ to total household energy use, as shown in equation 2 , where $\gamma$ is a simple constant, $\phi$ is a simple vector of coefficients for the household-specific vector $\zeta_{i}$, and $\epsilon$ is a randomly distributed error term.

$$
y_{i}=\gamma+\phi \zeta_{i}+\epsilon
$$

Perkins (2003) performed a linear regression, with household (delivered) energy as the target variable, in a study of 212 households in Adelaide, and found that site area was by far the most useful variable in predicting household energy use, responsible for explaining $25.1 \%$ of total variance in a model with an overall $r^{2}$ of $38.6 \%$. Household income, number of householders, and conditioned floor area explained $6.3 \%, 3.6 \%$, and $1.5 \%$ of variance, respectively, with the number of shared walls being negatively related to energy use and explaining $2.2 \%$ of variance. However, one would not expect a normal error term in a simple linear regression, and it is unclear if this was considered in the analysis by Perkins (2003).

Isaacs et al. (2006) used generalized linear regression models for specific household end-uses, and showed, interestingly, that a significant part of the energy savings made possible through a tightening of building regulations in the 1970s was largely 'consumed' in the form of greater thermal comfort and larger conditioned areas. The study also suggested that appliance ownership is not strongly related to the number of householders. 


\subsubsection{Household expenditure derived regression models}

Surveys of household expenditure, such as that conducted by the ABS (see Australian Bureau of Statistics (2004)), detail household spending in various categories, including spending on energy/fuel. If energy and fuel prices are also available for the period covering the expenditure survey, one can translate household spending on energy and fuel into household energy use. Care must be taken in this translation, however, as energy tariffs are usually not proportional to use.

As part of a larger analysis on energy use by households in Sydney Lenzen et al. (2004) found, using expenditure survey data, that the per capita indwelling (delivered) energy consumed by households was positively related to income, negatively related to the number of people in the household, and positively related to dwelling types associated with lower densities (i.e. detached houses).

Given the availability of household expenditure data, through the ABS, and the scarcity of large sample household energy use surveys, it is surprising that no detailed study of residential energy use has been undertaken using ABS household expenditure survey data. The analysis in the study by Lenzen et al. (2004) is somewhat cursory, given the article was concerned more broadly with the embodied energy used in all expenditure categories, but there is nothing preventing a detailed study of delivered energy alone. Given that the ABS expenditure surveys are nationwide, and allow access to unit-record (household level) data with detailed socio-demographic information, an extremely thorough study could be performed.

\section{$2.3 \quad$ Engineering models}

In contrast to regression models of household energy use, which seek merely to estimate a model that closely approximates household energy use, but which has no direct physical modelling basis, engineering models take an explicit physical 
approach to calculating household energy use.

The general mentality behind the engineering approach is that total energy use can be broken down into its constituent components: space heating; space cooling; cooking; audio-visual; and so on. Each of these tasks is undertaken by a particular device or appliance, and so provided one has detailed information about end-use efficiency, one can calculate the amount of energy required to perform each task. For example, given details on the ambient temperature, the heat-loss properties of a storage tank, the size of the tank, the thermostat setting, the conversion efficiency of the heating source, and the hot water demands of the household, it is possible to calculate the number of Joules required for any given hot water system. Doing so for 'typical' usage patterns gives a good indication, it is hoped, of the likely contribution of water heating to overall household energy use.

One area in particular that has received much attention is home heating/cooling. Computer simulation tools such as NaTHERS and BERS (now superceded by 2nd generation tools such as AccuRate), given detailed specification of floor plan, construction materials, insulation, orientation, location, ventilation, and climate, use mathematical descriptions of the various thermal transfer mechanisms to calculate the total heating/cooling energy required to maintain a given building at a fixed temperature. Predicting actual household energy use, however, is a good deal more complicated than this, and requires, crucially, additional assumptions about, or a detailed specification of, occupant behaviour. In the absence of a detailed behavioural model, one common approach has been to assume that space heating/cooling energy is proportional to the (unconstrained) energy required to maintain a fixed temperature, and a single coefficient is used to relate unconstrained total heating/cooling energy to actual usage. This approach was taken, for example, in Harrington and Foster (1999), and is also done in the heating/cooling component of the BASIX modelling software used by the NSW government to assess new residential de- 
velopment applications ${ }^{2}$.

As is clear from the above description, the principal difficulty in using engineering models is that they require extensive specification and calibration. They also do not allow for the easy inclusion of demographic information, as occupants (and their behaviour) are exogenous to engineering models, and must be estimated and/or specified separately, in addition to the specification of the engineering model itself. Harrington and Foster (1999) used engineering models to come up with future heating/cooling energy use forecasts under different building regulation scenarios in Australia. Isaacs et al. (2006) use a quasi regression/engineering approach for predicting the future household energy consumption in New Zealand households under different scenarios. The Greenhouse Calculator (Victorian Environmental Protection Agency, 2001), upon which the NABERS home energy assessment tool is based, is one of the more comprehensive generally available engineering method based tools for estimating household energy use. An engineering approach is used for all building shell rating schemes in Australia, usually through the use of tools such as NatHers/Accurate.

\section{Method}

Each of the three types of household energy study described: descriptive, regression, and engineering; have their own peculiar benefits. Descriptive studies provide valuable intuition and a broad understanding of household energy consumption and behaviour, while having no specific data requirements - they can be estimated from aggregated data. Regression studies require more detailed household level energy use and demographic data, and engineering models require very detailed appliance and behavioural data. Given that the focus of engineering models is on appliances and end-uses, they are most appropriate for analysis of changes to appliance efficiency, building shell design, and so on. For general analysis of household energy use in the absence of detailed appliance and

\footnotetext{
${ }^{2}$ Personal communication with Rob Helstroom, of the NSW BASIX team, 23/4/2006
} 
building stock data or assumptions, a regression approach is more appropriate.

Larsen and Nesbakken (2004) provide a review of regression (specifically CDA) and engineering models of energy use. After comparing engineering and econometric approaches, they conclude that, given the data sets typically available, and likely to be available in the near-term, the regression approach is more promising.

Given that the aim of this study is to help understand the broad socioeconomic and built-form drivers of household energy use, a regression approach is more appropriate than an engineering one. The datasets obtained for the analysis are of a form inappropriate for the calibration of engineering models in any case. For this study, a simple regression approach is taken, as the available data does not permit a CDA-style regression model to be reliably estimated, as detailed household appliance ownership data was not available ${ }^{3}$.

\section{Data}

Three datasets are used for the main regression analysis. The NSW Independent Pricing and Regulatory Tribunal (IPART) conducted two end-use household surveys (NSW Independent Pricing and Regulatory Tribunal, 2004, 2006), which consisted of 2604 and 2632 household level in-person questionnaires that were then matched with metered gas and electricity data obtained from utility companies. The third dataset was obtained from Randwick City Council, and also consisted of a household questionnaire (within Randwick City Council's borders only), combined with metered gas/electricity data. For the purposes of the following analysis, the main difference between the datasets is that the Randwick City Council data does not contain household income information, while the IPART data does. Given that household income exhibits strong spatial segregation (i.e. high income households tend to live together in high income areas), it is hoped that the lack of household-level income information for that

\footnotetext{
${ }^{3}$ Some appliance ownership information was available, but, after experiment, it became clear that it was not possible to use this to estimate a CDA-style regression model.
} 
data set will not distort the analysis greatly. The likely result of an inability to control for income is that estimates of energy use for households in Randwick Council (which covers a relatively affluent area of Sydney) will be higher than the Sydney-wide average, and that the income/wealth effects evident in the IPART data will 'spill over' into indirect indicators of income and wealth, such as dwelling type and dwelling size.

Both IPART datasets consisted of two parts: a random sample across Sydney (including the Blue Mountains), Wollongong, and Newcastle; and a specific lowincome sample. For an analysis which aims to provide insight into energy use in households generally, account needs to be taken of the non-random sample. The approach taken in NSW Independent Pricing and Regulatory Tribunal (2004, 2006) was to retain the non-random sample data and apply weights to households so that the (weighted) income distribution reflected that of the general population. In the following analysis, all households in the low income sample have been removed. In addition, due to the very different climatic conditions in the Blue Mountains, only data from Sydney, Wollongong, and Newcastle was analysed. Finally, a number of households with inconsistent or missing information were removed from the analysis ${ }^{4}$. The resulting dataset consisted of 1427 households (2003 dataset) and 1225 households (2006 dataset). Although data on Wollongong and Newcastle households was retained, excluding these from the analysis does not substantially affect results.

The Randwick City Council dataset contained similar information to that in the IPART dataset, with the exception (already noted) that household income information was unavailable.

For the IPART data, the target variable was the natural log of annualized delivered energy consumption. For the Randwick City Council data, the target variable was the natural $\log$ of average daily consumption. The log-transform was necessary in both cases as a simple linear regression on an untransformed target variable resulted in a non-normally distributed error term. In both cases,

\footnotetext{
${ }^{4}$ Households were excluded on the basis of such irregularities as having self-reported gas consumption but zero gas consumption obtained from the utility company
} 


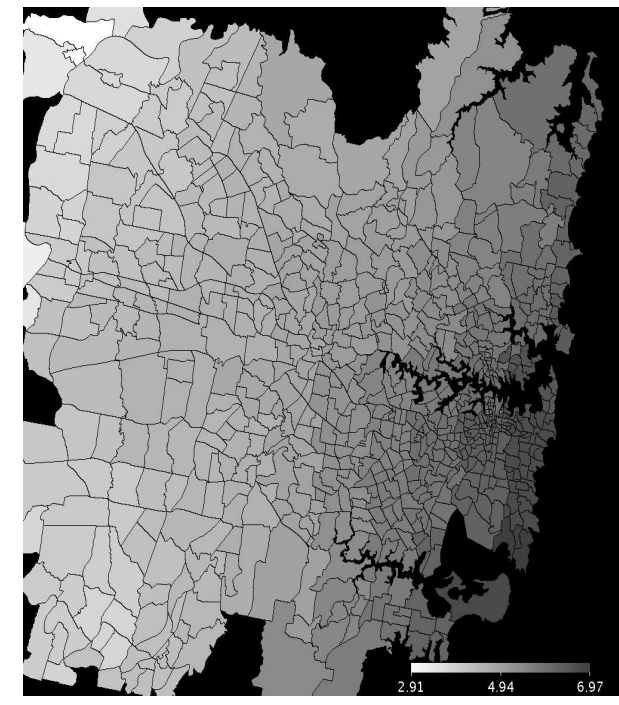

(a) Mean June Minimum

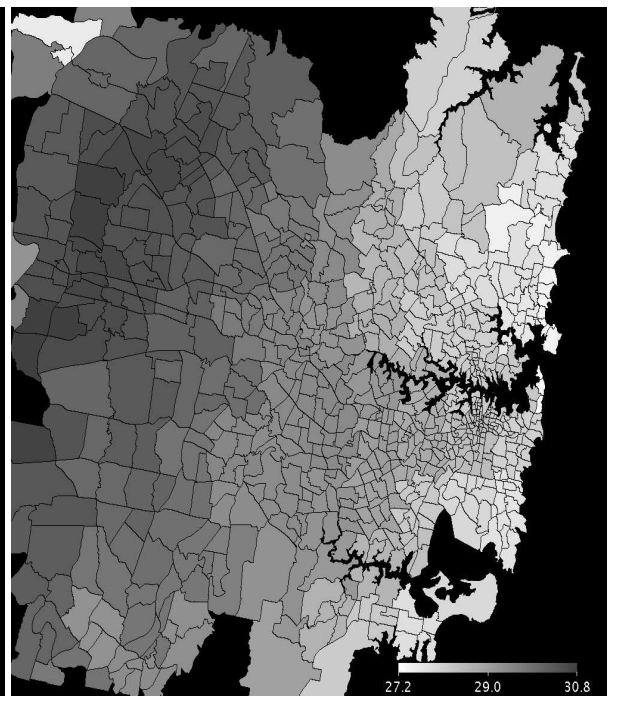

(b) Mean Dec. Maximum

Figure 1: Figure a shows mean daily minimum temperature (in ${ }^{\circ} \mathrm{C}$ ) in June 2000. Figure b shows mean daily maximum temperature in December 2000. Data Source: Australian Bureau of Meteorology.

gas and electricity consumption was combined into a total energy use target variable for the household. The combining of gas and electricity into a single target variable does pose some problems, as fuel choice is known to affect energy use. This is partly because the end use efficiency of gas and electricity differs for different tasks, and partly because different fuels are typically used for different tasks - gas for central heating and electricity for isolated room heating, for example. To capture these effects, dummy variables are used for households with gas connected, and for households that report using gas for specific purposes (cooking, hot water, etc.). Concern that the use of simple dummy variables to explain differences in end-use energy resulting from energy source is allayed by the fact that performing the same analysis on houses with electricity only (i.e. no gas) produces broadly similar coefficients - compare, for example, Tables 1 and 4 .

Because space heating and cooling represents a significant proportion of household energy use (Harrington and Foster, 1999; Bartels and Fiebig, 2000), 
and because Sydney has strong East/West climatic variation (see Figure 1), the dataset was augmented with fine-grained $\left(0.05^{\circ}\right.$ lat/long grid) information on temperature obtained from the Australian Bureau of Meteorology. Each household record in the IPART datasets was extended with additional climatic information. Because the spatial extend of the Randwick City Council data was more limited, this was not done for that data set.

Finally, it should be noted that only energy billed to the electricity and gas accounts of individual dwellings is considered. For units in apartment complexes that have significant common area energy use, this implies a significant underestimation of actual per household energy use. However, a re-analysis of the data from Myors et al. (2005) suggests that common area energy use is only likely to be significant for large apartments with lifts and (especially) pools. Since units in buildings greater than 3 storeys make up less than $8 \%$ of the units surveyed in the IPART data, the distortions involved by excluding common area energy use are unlikely to be large, and a separate analysis (unreported due to article length constraints) which excluded units greater than 3 storeys confirmed this.

\section{Analysis and Results}

The regression analysis proceeded in the usual manner, with the selection of model variables guided over numerous trials by a mixture of fit to data, common sense, and collinearity and residual analysis. Listing all available variables is impractical, but the main data sets are described in sufficient detail in NSW Independent Pricing and Regulatory Tribunal (2004) and NSW Independent Pricing and Regulatory Tribunal (2006).

Tables 1 and 2 show the regression coefficients obtained for semi-log regressions on the 2006 and 2003 IPART datasets, respectively. Given that only 3 years separate the data sets, one would expect coefficients to be broadly consistent, and this is the case for all variables apart from usegasheating, which is negative in 2003 and positive in 2006, and isowner, which is negative in 2006 and 
not significantly different from zero in 2003. Figure 2 compares the standarized regression coefficients ${ }^{5}$ for the two separate regression analyses.

To make sure the reader is clear on the exact form of the model estimated, the model obtained for 2006 (coefficients for which are presented in Table 1), is:

$\ln ($ TotalDeliveredEnergy $)=9.314+0.114 \times$ num_appliances $-0.093 \times$ isowner

$$
\begin{gathered}
+0.067 \times \text { num_bedrooms }+0.093 \times \text { numpeople } \\
+0.025 \times \text { income }+0.024 \times \text { hasaircon } \\
-0.17 \times \text { isflat }-0.081 \times \text { issemi } \\
+0.357 \times \text { hasgas }+0.108 \times \text { usegasheating }
\end{gathered}
$$

\begin{tabular}{|c|c|c|c|}
\hline & Coefficient & Standardized Coefficient & Significance \\
\hline constant & 9.314 & NA & $i 0.001$ \\
num_appliances & 0.114 & 0.243 & $i 0.001$ \\
isowner & -0.093 & -0.075 & 0.001 \\
num_bedrooms & 0.067 & 0.114 & $i 0.001$ \\
numpeople & 0.093 & 0.255 & $i 0.001$ \\
income (1-9) & 0.025 & 0.101 & $i 0.001$ \\
hasaircon & 0.024 & 0.046 & 0.040 \\
isflat & -0.170 & -0.082 & 0.001 \\
issemi & -0.081 & -0.048 & 0.029 \\
hasgas & 0.357 & 0.328 & 0.001 \\
usegasheating & 0.108 & 0.081 & 0.002 \\
\hline \hline adj. $r^{2}$ & \multicolumn{3}{|c}{0.484} \\
\hline RMS error & \multicolumn{3}{|c}{0.38415} \\
\hline
\end{tabular}

Table 1: Results from analysis of 2006 IPART data.

Tables 1 and 2 (and equation 3) report results from regressions containing only primary variables (i.e. variables collected directly in the respective surveys). Extensive experimentation with the inclusion of interaction variables indicated that a small additional improvement in the $r^{2}$ value could be achieved with the inclusion of interaction variables, but the picture does not change substan-

\footnotetext{
${ }^{5}$ That is, coefficients for variables that have been transformed to have zero mean and unit variance.
} 


\begin{tabular}{|c|c|c|c|}
\hline & Coefficient & Standardized Coefficient & Significance \\
\hline constant & 9.157 & $\mathrm{NA}$ & $\mathrm{i} 0.001$ \\
num_appliances & 0.114 & 0.247 & $\mathrm{i} 0.001$ \\
isowner & 0.005 & 0.004 & 0.837 \\
num_bedrooms & 0.089 & 0.145 & $\mathrm{i} 0.001$ \\
numpeople & 0.120 & 0.307 & $\mathrm{i} 0.001$ \\
income (1-9) & 0.023 & 0.091 & $\mathrm{i} 0.001$ \\
hasaircon & 0.095 & 0.083 & $\mathrm{i} 0.001$ \\
isflat & -0.198 & -0.091 & $\mathrm{i} 0.001$ \\
issemi & -0.075 & -0.043 & 0.041 \\
hasgas & 0.279 & 0.242 & $\mathrm{i} 0.001$ \\
usegasheating & -0.107 & -0.083 & 0.002 \\
\hline \hline adj. $r^{2}$ & \multicolumn{3}{|c|}{0.453} \\
\hline RMS error & \multicolumn{3}{|c}{0.424} \\
\hline
\end{tabular}

Table 2: Results from analysis of 2003 IPART data.

tially from the one painted by the regression results shown in Tables 1 and 2 . Table 3 shows the standardized regression coefficients for 2003/2006 with interaction variables included. The signs of all variables are as expected, except for the disagreement over gashw (positive in 2003, negative in 2006), and the disagreement over usegasheating and isowner, already observed in the regressions without interaction variables.

\begin{tabular}{|c|c|c|c|c|}
\hline & 2003 Std. Coefficient & $\mathrm{p}$-value & 2006 Std. Coefficient & $\mathrm{p}$-value \\
\hline constant & $9.365^{*}$ & $\mathrm{i} 0.001$ & $9.513^{*}$ & $\mathrm{i} 0.001$ \\
num_appliances & 0.264 & $\mathrm{i} 0.001$ & 0.244 & $\mathrm{i} 0.001$ \\
isowner & 0.003 & 0.881 & -0.068 & 0.003 \\
numpeople & 0.332 & $\mathrm{i} 0.001$ & 0.255 & $\mathrm{i} 0.001$ \\
isflat & -0.111 & $\mathrm{i} 0.001$ & -0.101 & $\mathrm{i} 0.001$ \\
issemi & -0.053 & 0.008 & -0.056 & 0.009 \\
hasgas & 0.385 & $\mathrm{i} 0.001$ & 0.229 & $\mathrm{i} 0.001$ \\
usegasheating & -0.054 & 0.013 & 0.09 & 0.001 \\
bed $\times$ income & 0.145 & $\mathrm{i} 0.001$ & 0.161 & $\mathrm{i} 0.001$ \\
aircon $\times$ rooms & 0.089 & $\mathrm{i} 0.001$ & 0.048 & 0.041 \\
gashw & -0.147 & $\mathrm{i} 0.001$ & 0.109 & 0.001 \\
solarhw & $\mathrm{NA}^{* *}$ & $\mathrm{NA}^{* *}$ & -0.059 & 0.004 \\
\hline \hline 2003 adj. $r^{2}$ & 0.501 & 2006 adj. $r^{2}$ & 0.494 \\
2003 RMS error & 0.404 & 2006 RMS error & 0.381 \\
\hline
\end{tabular}

Table 3: Standarized coefficient regression results for 2003 and 2006 with interaction variables. ${ }^{*}$ Unstandardized. ${ }^{* *}$ Information unavailable for 2003 analysis. 


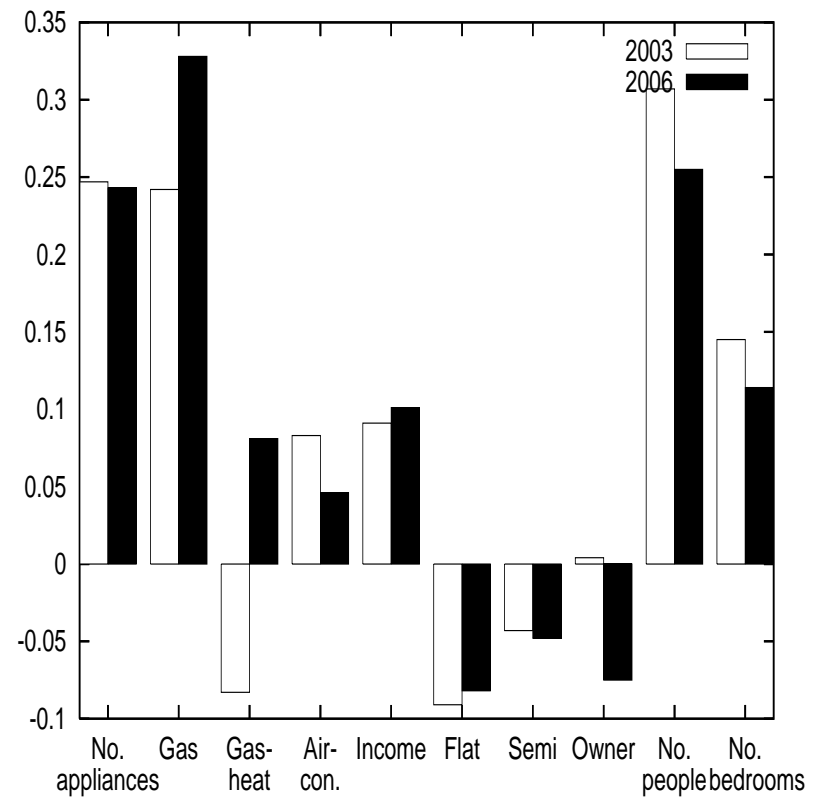

Figure 2: Comparison of 2003 and 2006 standarized regression coefficients.

Because the use of gas is associated with higher household energy use, and the exact reason for this is unclear, separate regressions using households without gas connections were performed. The results from a regression on households without gas in the 2006 IPART data-set is shown in table 4, and suggests that the inclusion of fuel-choice does not greatly distort the values of the principal factors influencing energy use.

\begin{tabular}{|c|c|c|c|}
\hline & Coefficient & Standardized Coefficient & Significance \\
\hline constant & 9.4 & NA & $i 0.001$ \\
num_appliances & 0.115 & 0.278 & $i 0.001$ \\
isowner & -0.076 & -0.075 & 0.013 \\
num_bedrooms & 0.043 & 0.088 & 0.009 \\
numpeople & 0.08 & 0.257 & $i 0.001$ \\
income (1-9) & 0.024 & 0.107 & $i 0.001$ \\
hasaircon & 0.083 & 0.087 & 0.003 \\
isflat & -0.141 & -0.085 & 0.006 \\
issemi & -0.084 & -0.053 & 0.061 \\
\hline \hline$r^{2}$ & \multicolumn{3}{|c}{0.331} \\
\hline
\end{tabular}

Table 4: Results from analysis of 2006 IPART data (households without gas only. $\mathrm{N}=984)$. 
The semi-log nature of the regression model estimated from the 2003 and 2006 IPART data sets make interpretation less than straightforward. A helpful way of viewing a semi-log model is to consider that each variable coefficient can be interpreted as the expression of how much, in percentage terms, a unit change in a given variable, changes overall energy use. For example, taking the coefficient of 0.255 for the numpeople variable from the regression on 2006 IPART data in Table 3, we can see that an increase (decrease) in household size of 1 person results in an increase (decrease) in energy use of $29 \%(22.5 \%)$, as $e^{0.255}=1.29$ and $e^{-0.255}=0.775$. Figure 3 shows the estimated percentage change in energy use resulting from a unit positive/negative change in each explanatory variable (barring those relating to fuel choice) in the 2003 and 2006 IPART models without interaction terms ${ }^{6}$ shown in Tables 1 and 2. The most interesting finding, from both a research and policy perspective, is that, is that household energy use, is around $15-20 \%$ lower in a flat, holding other variables constant. That is, the regression models estimated on the IPART data suggest that moving the same household from a detached house to a unit with the same number of bedrooms will result in a 15-20\% reduction in delivered energy use. This is at least partly (and possibly wholly) related to space heating/cooling and dwelling size - an n-bedroom unit is, on average, smaller than an n-bedroom house. Such a decrease seems, naively, quite plausible. Given $38 \%$ of delivered energy use is used for space heating/cooling Harrington and Foster (1999), assuming a $20 \%$ reduction in the volume of space to be conditioned ${ }^{7}$, and a $30 \%$ increase in heat/cool efficiency due to shared walls and the like (Harrington and Foster (1999) assert that attached dwellings are 36\% more efficient, while Miller and Ambrose (2005) estimate a 33.7\% efficiency increase for attached dwelling per unit area), one would expect a saving in total energy use of around $17 \%$

\footnotetext{
${ }^{6}$ The models without interaction terms are chosen because of the difficulty in interpreting unit changes in interacted variables.

${ }^{7}$ Data generally available from the ABS and other sources usually provide average floor space for detached/other dwellings, so do not allow for a direct comparison, as detached dwellings have more bedrooms on average than attached dwellings. Thus, while most would accept that a unit will be smaller than a house with the same number of bedrooms, the $20 \%$ figure quoted is based solely on the author's judgement.
} 


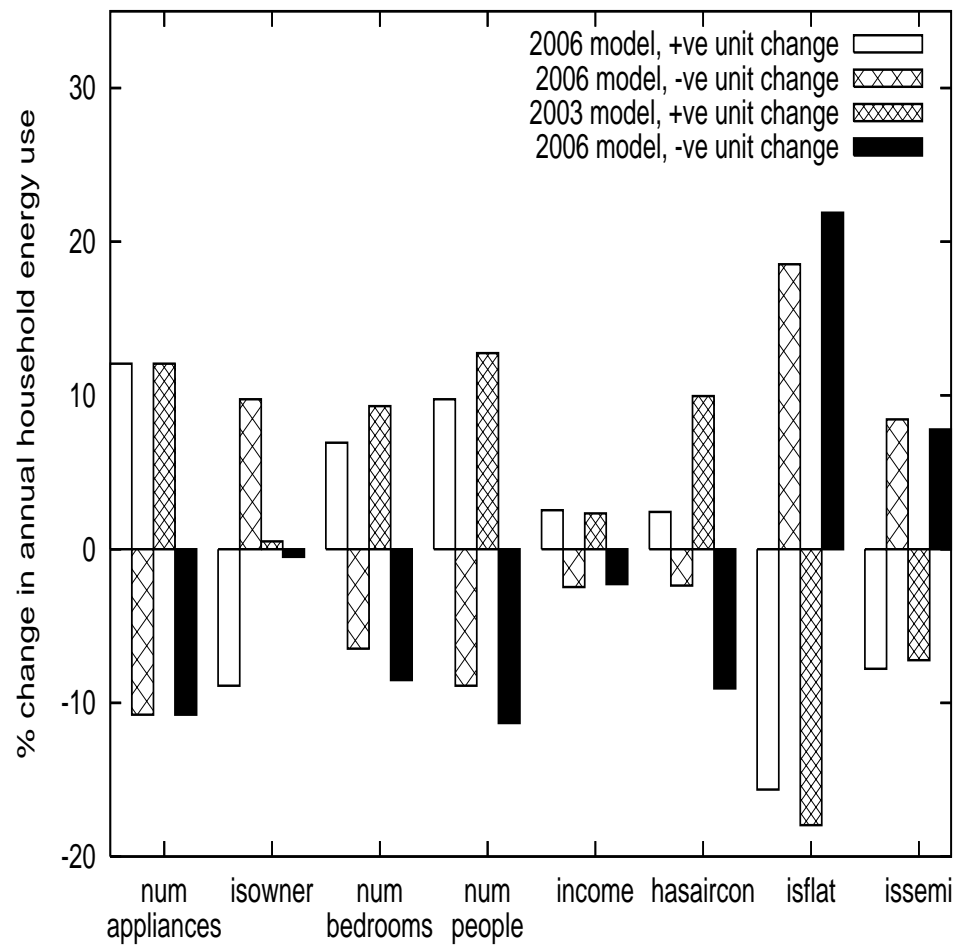

Figure 3: Change in energy use (MJ per household per annum of delivered energy) from unit changes to explanatory variables, calculated from regression models detailed in Tables 1 and 2.

$(0.38-0.38 \times 0.8 \times 0.7 \approx 0.83)$, which nicely fits the results presented here.

Table 5 shows the regression model on the smaller $(N=162)$ dataset from an energy audit of households in Randwick City Council. The target variable was the natural logarithm of average daily household energy use, in MJ. The main factors influencing household energy use are dwelling size, eveningoccupancy (the number of people typically home on a week-night), winter heating hours: the typical number of hours a heater is used in winter, pool pump: whether or not the household has a pool pump, and hasclothesdrier: a 0/1 dummy for whether the household has a clothes drier. The pool pump variable is perhaps partly a proxy for income, as only the wealthier households could afford a detached dwelling with room for a pool in Randwick. The findings that strongly relate dwelling size and evening occupancy to energy use are in broad agreement with the results from the IPART analysis. Interestingly, variables 
describing dwelling type were found to be insignificant once dwelling size was included. This suggests that dwelling type may be acting partly of wholly as a proxy for dwelling size in the IPART regression results, since, even though a separate variable (numbedrooms) was included as a proxy for dwelling size in those cases, it is an imperfect proxy, as a unit is likely to be smaller than a house with the same number of bedrooms. The inclusion of variables describing households attitudes to climate change and energy conservation, which was available in the survey data, did not produce any improvement in the model. Including the tenure status of the household (renter/owner) did not improve model fit either, as was found in the regression on 2003 IPART data.

\begin{tabular}{|c|c|c|c|}
\hline & Coefficient & Standardized Coefficient & Significance \\
\hline constant & 2.707 & $\mathrm{NA}$ & $\mathrm{i} 0.001$ \\
winter heating hours & 0.049 & 0.239 & $\mathrm{i} 0.001$ \\
dwelling size (squares) & 0.005 & 0.408 & $\mathrm{i} 0.001$ \\
eveningoccupancy & 0.164 & 0.325 & $\mathrm{i} 0.001$ \\
pool pump & 0.051 & 0.205 & $\mathrm{i} 0.001$ \\
hasclothesdrier & 0.126 & 0.092 & 0.087 \\
\hline \hline \multicolumn{3}{|c|}{0.593} \\
\hline
\end{tabular}

Table 5: Results from analysis of Randwick City Council Data (N=162).

Before further discussing the results of the preceeding analyses, it is useful to revisit the data analyzed in Myors et al. (2005). Although the authors were careful themselves to make no such claim, this study is now not infrequently used to suggest that units, and especially high-rise units, are more energy intense than detached dwellings. Figure 4 shows a re-analysis of the same data, and indicates that while there does appear to be greater overall per-capita energy use in high rise buildings compared to low-rise and villas/townhouses, it is possible that this is largely a result of the provision of luxury common area features (heated pools, spas, etc.) rather than anything relating particularly to built form. This possibility, together with the high variance in the energy use figures for high rise dwellings in Myors et al. (2005), suggest it is unwise to draw conclusions about the energy-use implications of high rise apartments without a more thorough 


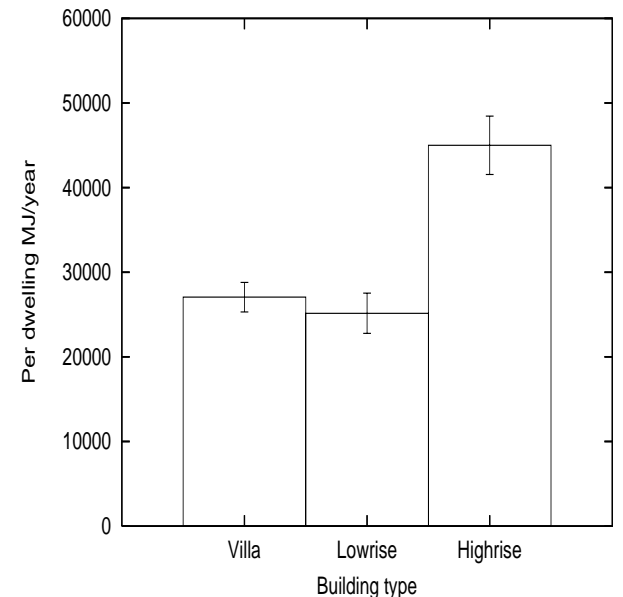

(a) Original Groupings

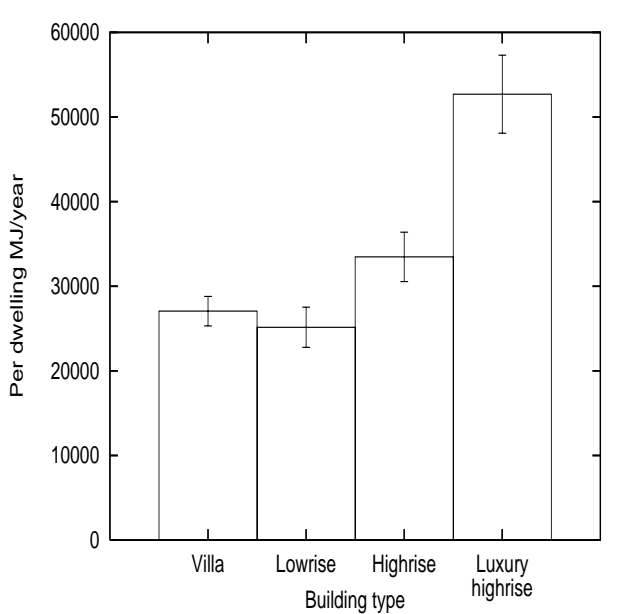

(b) Alternate Groupings

Figure 4: Comparison of per-dwelling energy use under groupings used in Myors et al. (2005) (left) with alternate grouping that distinguishes luxury high-rise from non-luxury high-rise (right). Luxury buildings are defined as those containing a pool/spa. Highrise is defined as those buildings with a lift. Villa includes townhouses/semi-detached. Error bars show standard error of the mean, not sample standard error. Data Source: Same dataset as analysed in Myors et al. (2005), obtained from Paul Myors, Energy Australia.

analysis of energy use in high rise dwellings.

\section{Discussion}

The regression results provide a general picture of household energy use that is, on the whole, difficult to object to. All other things equal, wealthier households use more energy, larger households use more energy, and households in larger dwellings use more energy. Equally uncontentious is the finding, from the analysis of IPART data, that households with air-conditioners use more energy. It is unclear from the analysis whether tenure status has an independent effect on energy use or not - both possibilities remain open. From a planners perspective, an interesting finding is that semi-detached dwellings and units are associated with lower energy use, all other things equal. It is unclear, however, whether this is due mainly to the smaller floor area of attached dwelling types, or due to the thermal benefit of having shared walls (demonstrated in thermal 
simulation models). Perhaps it is both, although the results of the regression on Randwick City Council data provides some weak evidence that the reduction in floor area is the more important factor. While thermal modelling studies of attached and detached dwellings suggest that for equivalent climate, orientation, and insulation levels, attached dwellings require less heating/cooling energy per unit area to maintain a particular level of thermal comfort than do detached dwellings (Miller and Ambrose, 2005; Harrington and Foster, 1999), it is unclear whether this translates into lower energy per $\mathrm{m}^{2}$ in practice. Considered together, however, the smaller per unit area energy use estimated in thermal modelling studies, along with the smaller floor areas typical of attached dwellings, add credibility to the negative parameters associated with attached dwellings in the regression analysis.

Despite the highly variable nature of household energy use, the regression results are instructive of general trends, and the $r^{2}$ is comparable with other regression models of household energy use: Perkins (2003) explained $38.6 \%$ of variance; Bartels and Fiebig (2000) 66\% of variance; and Larsen and Nesbakken (2004) $48 \%$. Evidence for the highly idiosyncratic nature of households energy consumption is found in almost all studies of household energy use. The comments by Isaacs et al. (2006) in their large ongoing study of New Zealand households give some indication of the difficulty in explaining household energy use through regression models:

Although the overall average may fit with preconceived expectations, the extremes are not as obvious.

Conventional application of statistical analysis raises some interesting questions - are the extreme values statistical anomalies (and should be excluded from a robust analysis) or are they realistic reflections of the huge spread of energy use? HEEP results suggest that they are not measurement outliers. (page 9)

The finding (in the IPART regressions) that households with gas connected 
use more energy is unsurprising, given the typically lower end-use efficiency of gas. Pears (1998), for example, used an overall end-use conversion factor of 1.5 to correct for the lower end-use efficiency of gas. The inconsistent results for the presence of gas central heating also suggest that part of the energy used in gas central heating is captured by the hasgas dummy variable. While the practice of relying on dummy variables to capture the effect of fuel choice is questionable, it does not seem possible to do much better with the available data. Use of interaction variables (such as numbedrooms interacted with mainlyusegasheating) did not markedly improve estimated models. Analysis of households that rely solely on electricity suggested that the inclusion of the fuel-choice related dummy variables was not too distorting (see Table 4).

The inability of the analysis to detect a significant effect from any regional climate variables is surprising. Given that space heating and cooling in Australia constitute around $38 \%$ of delivered energy use (Harrington and Foster, 1999), and inter-city variation in heating/cooling energy use due to differing climate is easily demonstrated, it is hard to believe that the climatic variation observed over the study region does not influence household energy use. The difficulty in detecting such variation is that climate varies primarily east/west in Sydney, but household income also varies strongly east/west, as wealthier households are more likely to live in eastern harbour and sea-side suburbs. Land economic forces also dictate that the suburbs with high land values, have higher dwelling densities, and so are more likely to contain smaller detached dwellings and attached dwellings. Demographic variation and housing preferences are such that the ocean and harbour-side suburbs are also less likely to be occupied by households with children. These factors, together with the high unexplained variance in household energy use, make it difficult to detect the effect of climate, and it seems likely that some climatic effect is incorrectly attributed to householdtype, income or dwelling-type coefficients. Difficulties in adequately controlling for spatially correlated variables is of course commonplace in urban research.

Another interesting finding from the Randwick Council data is that attitudes 
to energy conservation and climate change are not strongly related to actual metered energy use. While that data-set was small, prior research has also suggested that attitudes are unreliable predictors of actual use (Mullaly, 1999), as households are prone to overestimate their own energy conservation measures.

The preceeding analysis used a data set that is, to the author's knowledge, the largest yet used in an investigation of in-dwelling energy use in Australia. Given this fact, and the fact that the results indicate that multi-unit dwellings are more energy efficient than detached dwellings (all other things equal), it seems premature to conclude, as some have done, that increases to urban density achieved through multi-unit development will result in higher energy use. Consider Randolph and Troy (2007), for example:

... Myors et al. (2005) have shown that per capita greenhouse emissions from high rise flats in NSW, at 5.4 tonnes of $\mathrm{CO}_{2}$ per year, are significantly higher than the NSW average of 3.1 tonnes of $\mathrm{CO}_{2}$ per year. While not specifically focusing on dwelling type per se, research by Foran (2006) has shown household greenhouse emissions in Canberra and Perth, based upon an assessment of total household energy consumption, is higher in inner city locations compared with suburban locations .... Foran's analysis suggests strongly that urban density is positively related to total greenhouse gas emissions, with the implication that higher density areas less environmentally sustainable.

Randolph and Troy (2007)[page 19], italics theirs.

But this is far too strong a conclusion, and is symptomatic of a more general trend in urban planning of relying on summary statistics that may mask more complex driving factors. In the above quote, the authors rely on a comparison of recently constructed high rise dwellings, many containing luxury features (spas, pools), with general detached housing stock, much of which is quite old. A more useful comparison would be a sample of recently constructed high-rise with 
recently constructed detached dwellings. The authors compound their inference errors by then relying on a study by Foran (2006) to support their assertion that 'higher density areas (are) less environmentally sustainable'. But there is no support for such an assertion, either in the analysis by Foran, or by similar work by, for example, Lenzen et al. (2004). These input/output method studies, which attempt to calculate the energy embodied in each dollar of expenditure, show, unsurprisingly, that higher income is associated with higher energy use. Because per capita income is in general higher closer to the $\mathrm{CBD}^{8}$, this results in per capita energy use being higher in the denser areas closer to the CBD. Without further analysis, however, one cannot claim, as Randolph and Troy (2007) do, that urban density has any effect. In fact, the regression analysis in Lenzen et al. (2004)[page 391] suggests that there is no strong statistical association between higher urban density and per-capita energy use, if one controls for other factors.

The point the author wishes to make here is not that higher density housing is more energy efficient than studies such as Myors et al. (2005); Randolph and Troy (2007); Perkins et al. (2007) suggest. Personally, the author finds much of the existing data on embodied and operational energy use in high rise dwellings to be troubling. However, there is a danger that a conventional wisdom will develop in planning circles about the energy intensity of apartments that is simply not (yet) supported by the available evidence. Furthermore, there is the potential for a division of researchers along the same old fault line that has been running through much urban analysis in Australia for decades now: density. Urban researchers who favour higher density living can find ample evidence that average per-dwelling energy use is lower in attached dwellings. Others who wish to argue against increasing density can find ample evidence that average per-capita energy use is lower in detached dwellings. By relying on summary average statistics, and selecting the basis for comparison (per capita, per unit area, per dwelling, etc), researchers can find whatever 'evidence' they need to support a particular position. The ossification that ensues makes genuine

\footnotetext{
${ }^{8}$ This trend is strongest in Sydney, where Lenzen et al. (2004)'s work was conducted, but is also true in Canberra, where Foran performed his analysis.
} 
research progress very difficult (Gleeson, 2007).

The fact that different units can be used to report in-dwelling energy and greenhouse emission statistics (per capita, per unit area, per dwelling, etc) is itself an obstructing factor. Championing one reporting unit as the 'best' for comparison purposes is unhelpful. Restricting ourselves to in-dwelling energy, the base question that we are should be trying to answer is: What are the energy use implications of particular housing strategies?, and, importantly Which strategies are politically achievable?. These are metropolitan scale questions, not dwelling or household specific ones. The second question is of prime importance because the estimated energy savings of shifting a family household from a detached dwelling into an attached one is likely to be irrelevant if such households are deeply opposed to such living conditions, as suggested by Troy (1996), and also by the residential discrete choice model estimated for Sydney in Yates and Mackay (2006). Similarly, studies showing lower per-capita energy use in detached dwellings are of limited use if significant proportions of childfree households prefer to live in an attached dwelling if this allows for better accessibility and access to services (as suggested by Vipond et al. (1998)). More thorough analysis is needed which looks at the projected household mix in our cities, and the likely housing preferences of those households. Work with such a metropolitan-scale focus has been rare in Australian planning research since the pioneering work on urban structure and energy use by Newton (1997), although some recent Australian work-in-progress (reported in Rickwood et al. (2007)) is also city-scale. Rather than asking the simple question: 'What is the most sustainable dwelling type', we can instead start to think about the tradeoff between meeting future housing preferences, and reducing the in-dwelling energy use in our cities. If, for example, substantial savings in energy use are only achievable through planning policies that essentially force people to make housing choices that they are strongly opposed to, then it may be better to concentrate on changes to energy tarrifs, appliance efficiency, power generation, and building/development design. 


\section{References}

Australian Bureau of Statistics (2004). Household expenditure survey and survey of income and housing: User guide, 2003-04. Catalogue Number 6503.0.

Australian Bureau of Statistics (2005). Environmental issues: People's views and practices. Catalogue Number 4602.0.

Australian Bureau of Statistics (2007). Australian social trends. Catalogue Number 4102.0.

Bartels, R. and Fiebig, D. (2000). Residential end-use electricity demand: Results from a designed experiment. Energy Journal, 21(2):51-81.

Bunker, R. and Holloway, D. (2006). Planning, housing and energy use: A review. Urban Policy and Research, 24(1):115-126.

Foran, B. (2006). Ecological footprints of cities. Fenner Conference on Urbanism, Environment \& Health.

Gleeson, B. (2007). Keynote address: The endangered state of Australian cities. State of Australian Cities conference.

Harrington, L. and Foster, R. (1999). Australian residential building sector greenhouse gas emissions 1990-2010. Technical report, Australian Greenhouse Office.

Isaacs, N., Camilleri, M., French, L., Pollard, A., Saville-Smith, K., Fraser, R., Rossouw, P., and Jowett, J. (2006). Energy Use in New Zealand Households. Study Report 155. Branz Ltd, Judgeford, New Zealand.

Larsen, B. and Nesbakken, R. (2004). Household electricity end-use consumption: Results from econometric and engineering models. Energy Economics, 26:179-200.

Lenzen, M., Dey, C., and Foran, B. (2004). Energy requirements of Sydney households. Ecological Economics, 49:375-399. 
Miller, A. and Ambrose, M. (2005). Energy efficient multi-storey residential developments. Conference on Sustainable Building South East Asia, Malaysia.

Mullaly, C. (1999). Home energy use behaviour: a necessary component of successful local government home energy conservation programs. Energy Policy, 26:1041-1052.

Myors, P., O'Leary, R., and Helstroom, R. (2005). Multi unit residential buildings energy and peak demand study. Energy News, 23(4):113-116.

Newton, P. W. (1997). Re-shaping Cities for a more sustainable future. Australian Housing and Urban Research Institute.

NSW Independent Pricing and Regulatory Tribunal (2004). Residential Energy use in Sydney, the Blue Mountains and Illawarra. Research Paper RP27, ISBN 1920987053.

NSW Independent Pricing and Regulatory Tribunal (2006). Residential Energy use in Sydney, the Blue Mountains and Illawarra. Research Paper RP28, ISBN 9781921328008.

Pacific Power (1994). The Residential End-Use Study. Pacific Power, available at http://www.energyrating.gov.au.

Pears, A. (1998). Stategic Study of Household Energy and Greehouse Issues. Environment Australia, available at: http://www.energyrating.gov.au/library/pubs/pears-ago1998.pdf.

Perkins, A. (2003). How significant an influence is urban form on city energy consumption for housing and transport? State of Australian Cities conference proceedings.

Perkins, A., Hamnett, S., Pullen, S., Zito, R., and Trebilcock, D. (2007). Transport, housing and urban form: The life cycle transport and housing impact of city centre apartments compared with suburban dwellings. State of Australian Cities Conference. 
Randolph, B. and Troy, P. (2007). Research Paper No. 7: Energy consumption and the built environment: A social and behavioural analysis. City Futures Research Centre, UNSW.

Rickwood, P., Giurco, D., Glazebrook, G., Kazaglis, A., Thomas, L., Zeibots, M., Boydell, S., White, S., Caprarelli, G., and McDougal, J. (2007). Integrating population, land-use, transport, water and energy-use models to improve the sustainability of urban systems. State of Australian Cities Conference.

Rickwood, P., Glazebrook, G., and Searle, G. (2008). Urban structure and energy - a review. Urban Policy and Research, 26(1):57-81.

Troy, P. (1996). The Perils of Urban Consolidation: A Discussion of Australian Housing and Urban Development Policies. Federation Press.

Troy, P., Holloway, D., Pullen, S., and Bunker, R. (2003). Embodied and operational energy consumption in the city. Urban Policy and Research, 21(1):9-44.

Victorian Environmental Protection Agency (2001). Australian Greenhouse Calculator (CD-ROM). EPA Victoria. ISBN: 0643065946.

Vipond, J., Castles, K., and Cardew, R. (1998). Revival in inner areas. Australian Planner, 35(4):215-222.

Yates, J. and Mackay, D. F. (2006). Discrete choice modelling of urban housing markets: A critical review and an application. Urban Studies, 43(3):559-581. 